\title{
Enhancing university -industry collaboration: What are the drivers of academic researchers' involvement in industry?
}

\author{
Mostak Ahamed Galib, Kamrun Nahar Munny, Akmal Khudaykulov \\ School of Management Science, Wuhan University of Technology, China \\ Faculty of Industrial Management, European University of Bangladesh, Bangladesh \\ School of Management, Huazhong University of Science and Technology, China
}

\begin{abstract}
Industry engagement of researchers plays an important role in organizational outcomes such as increased number of licenses and patents, innovation, successful R\&Ds and consequently increased efficiency and economic performance. The gap between the theory and practice of industry engagement are identified and a scientific model of industry engagement of is developed in this paper. The research model depicts the possible generation of the industry engagement as an outcome. Through a detailed review of all factors belonging to the scope of motives that are opportunity-driven, key factors that are most conducive to researchers' industry engagement were identified. We have proposed the relationship between compensation and recognition, access to resources, application of the research, networking opportunities, and industry problem solving with industry engagement. This study supports the notion that industry engagement is essential for improving organizational learning capability and innovation performance. Significant implications for organizations exist, as they are aware of which parts of their operations and conditions will drive relevant talent to engage in the organizations' work.
\end{abstract}

Keywords: Industry Engagement, Motives for Industry engagement, Organizational Learning Capability, Organizational Innovation Performance

\section{INTRODUCTION}

Scientists engaging in industry is a driver of organizational innovation performance as Balachandra and Friar (1997) state. Research and development (R\&D) is the basis of product and process innovations, making the R\&D department the lifeblood for most organizations. Prior studies showed that improved R\&D efforts are linked to a rise in innovative products which consequently facilitates market share improvement and competitiveness of organizations (Armbruster, Bikfalvi, Kinkel and Lay, 2008). Innovation requires the implementation of creative ideas which scientists effectively bring into realization through research. Organizations apply these research results into the system by a process called organizational learning. Engagement of talents that contribute to organizational performance particularly in innovation is a matter of concern for organizational managers worldwide. The term industry engagement is embedded in academic research, which is considered largely as drive for innovation performance by swerving organizations from doing routine operations into unique and new methods that are efficient and effective.

Significant attention has been given to linkage of industry engagement to innovation results of organizations. Several studies observe that when scientists engage in the industry it initially results in greater employee performance, which further leads to enhanced organizational performance in terms of innovation (Perrin, 2006; Gallup, 2006). Industry engagement provides employees with an opportunity to invest themselves in their innovative work and also nurtures innovation within the organization. Research on the consequences of scientists' engagement indicates that engagement may result in new positive and healthy working environment for an organization. A study by Gallup (2006) reported improved performance of the organization as a whole with more scientist engaged in the industry. In 


\section{Mostak Ahamed Galib, Kamrun Nahar Munny, Akmal Khudaykulov \\ Enhancing university -industry collaboration: What are the drivers of academic researchers' involvement in industry?}

addition, Kahn (1990) states that industry engagement may lead to creativity, mindfulness and authenticity of enhanced overall productivity of organizations.

Goals such as the attainment of innovation performance of an organization are extremely important part of the initiation of the industry engagement process because goals stimulate energy, focus, and intensity from scientist in the quest for bringing innovation results. According to Macey et al. (2009), the accomplishment of innovation results cannot occur without an objective which calls for the alignment of goals both from the individual scientists and organizational goals. Such an alignment serves as the guiding link that ensures a strategic focus of engagement toward innovation performance. Scientists engage themselves in tasks that are important for the realization of an organization's goals and objectives. Hence, during this stage, scientists are aware of and understand clearly the organizational goals and objectives and with it they should set their own goals. These goals correspond with the researcher's motives. However, insufficient collaboration between industry and research, insufficient employment of researchers in the industry is prevailing. The part of the cause for this condition may lie in neglecting the motives that drive the scientists to get involved in industry either on a full time or project basis. Existing studies have failed to quantitatively evaluate motives' contribution to industry engagement. Without knowing the key motives, valid organizational practices for industry engagement enhancement cannot be designed and implemented. In this study, we explore how various factors which researchers have identified as relevant motivators affect individuals' industry engagement.

\section{MOTIVES IMPACTING RESEARCHERS' INDUSTRY ENGAGEMENT}

\section{COMPENSATION AND RECOGNITION}

According to the motivational theories, financial security and stability have shown to be significant drivers of engagement in certain activities and performance of behaviors. While academic life cycle theory shows that scientists invest more in their human capital and reputation development at earlier stages of their careers but on the later stage they invest more on monetary returns pushing them to be involved in the industry after their career goals have been fulfilled. Studies conducted by Levin et al. (1991), Audretsch and Stephan (1999) have shown this change of goals in early and later stages of life cycles, whereby, scientists focus much on commercial activities as they approach the later stages to plan for their life after retirement. Stephan and Levin (1992) found that scientists reach out to the industry with the objective of capitalizing on their expertise, this move is important to them in gaining higher monetary value through patents. In this regard, we see economic gains as push factor among scientists to be engaged in the industry. Monetary value serves as motivating factor in science because organizations financially reward their productive scientists. Productivity of scientific research is not just rewarded from the organization employing a particular scientist but other institutions offering research grants.

However, some scientists value reputation and recognition of their research work accomplished more than monetary compensation. Earlier study done by Merton (1957) demonstrated that among the main factors leading scientists to do research in the industry is recognition. Traces regarding the significance of reputation as a motivating force in science are readily apparent. In the process of project participation, scientist performs behaviors which often results in positive outcomes. For that effort, their work is rewarded which produces a feeling of satisfaction which, in turn, leads to a desire for engaging further and being a part of industrial activities. According to Koeske et al. (1994), job satisfaction is dominant factor that draws effective scientist engagement within the industry. Owen-Smith and Powell's (2001) qualitative study offers some insights that backup the notion of academics being attracted by monetary profits that accumulate when involved in the industry than academia.

Additionally, prior studies establish a direct relationship between incentives (income, rewards, and bonuses) and industry engagement. For instance, in a qualitative study performed by Albert et al. (2006) tests an academy - industry relationship; 16 percent among so many factors investigated stated that 


\section{Mostak Ahamed Galib, Kamrun Nahar Munny, Akmal Khudaykulov \\ Enhancing university -industry collaboration: What are the drivers of academic researchers' involvement in industry?}

they are engaged in the industry because of personal income. Economic compensation is considered as an important motivator which was proven by Deeprose (1994). He states that incentives in the form of money may not be the best motivator but without it, many engaged scientists will be strongly demotivated. Economic rewards are highly valuable in showing the worthiness of work done by an employee; in our case, for an industry involved researcher, self-esteem and sense of achievement is essential for reputational status. Albert et al. (2006) studies non-pecuniary rewards, such as approval toward promotion and occupation as relevant push factors leading to industry involvement. This above supporting arguments and literature leads to the development of the following propositions.

Proposition 1: Compensation has a positive relationship with industry engagement

Proposition 2: Recognition has a positive relationship with industry engagement

\section{NETWORKING}

Prior studies show that many scientists engage in networking for social capital and the reviewed prior studies all point to the benefit of collective value shared within the network circle. Network members enjoy benefits of reciprocity which inclines that people do favors to each other. Researchers expand their network in the industry for various reasons e.g. exchanging ideas for which they can build new research. The rational choice theory posits that social capital cannot be achieved by those that do not socialize; therefore, groups are necessary to create a set of benefits for the network depending on individuals or groups to exploit and reap from such networks for private agendas. In this sense, the essence of collectiveness is key to generating social capital, though individualism still exist, however, it forms a bridge between the approaches to collectivism versus individualism (Ferragina, 2010). A study by Nahapiet and Ghoshal (1998) views social capital in three perspectives, namely, norms, values or preferences essential for collective innovative project. Maskell and Lorenzen (2004) adds that mutual trust being shared drives the accomplishment of these innovative projects in engagement of academics and industry. In addition, they argue that the existence of a set of shared values such as commitment, reciprocity and trust are required in the development of the shared innovation strategy.

Cooke et al. (2005) states that profitable exchange and cooperation of peers involved in the industry revolves trust which is crucial for the efficiency of social structure development within the social capital context. Both economists and sociologists recognize the reliance between social capital and wealth accumulation (Grootaert, 1998; Zak and Knack, 2001). Bigger social capital produces larger opportunities to have access to more funds. Parsons (1951) argued that to develop a successful network means scientists rationalize in broadening their connections in industry, scientists values such as social capital as necessity of industry based networking (Blau, 1972). Networks that generate trust are operational as monetary lubricant with lesser costs and they form new ways of pool resources and business opportunities for prosperity (Fukuyama, 1996).

Networking deracinates immense thinking and talents out of different people to promote learning, creativity and innovation. When similar and different minded people meet, exchange and share ideas openly, this stretches creativity and innovation by gaining new concepts, perspectives or creative ways in handling tasks and thus, thinking is acquired. Thus, scientists expand their networks in the industry as possible to widen their circles of influence and open doors for opportunity which may not be instantly gained but a long-term link. Communication and trust are key factors in establishing an effective social capital that consequently leads to a rise in efficiency of actions (Nahapiet, et al., 1998). Burt (1992) adds that flow of information (Fukuyama, 1995) promotes collaborations and cooperation for creativity and innovation toward creating shared value by reducing the costs associated with monitoring and transaction processes.

The power of knowledge is gained through networking with others, which molds the researchers and their idea or research to be visible in a large platform of industries. This visibility or exposure in both academia and industry is critical to personal and professional success. However, according to a study by Brocke et al. (2009), the main motivation of people to network is to stay in contact with friends that already engaged in the industry which are followed by the intention to be well-versed about industrial 


\section{Mostak Ahamed Galib, Kamrun Nahar Munny, Akmal Khudaykulov \\ Enhancing university -industry collaboration: What are the drivers of academic researchers' involvement in industry?}

changes. Typically, most studies expect scientists to network in order to connect to others with whom they share similar interests. Contrary to this, Brandtzaeg and Heim (2009) found that networks are mainly formed and followed to build new and pleasurable relations of new people with different thinking. In this way, a scientist is not limited to certain direction of thinking pushing them out of academia. Furthermore, the motive of engagement based on networking is the main capability to gather feedback from peers and strengthen the bonds of relationship which is part of the developmental challenges of emerging researchers toward career growth.

The power of the networks provide three unique advantages, namely, access to private information, access to diverse skill sets and power to grow as a scientist (Uzzi and Dunlap, 2005). This network power is essential for further research decisions, as obviously public information is easily accessible from various sources but private information is subjectively focused which means that the value of information only passes to close contacts where trust plays a main role. Elaborating on opportunities arisen from networking in the industry benefits researchers to learn about how to conduct business that drives them to start up their own entrepreneurship, understand the industry they are involved in better and get to know the challenges their contacts face with how they resolve such challenges.

Harrin (2014) argues that meeting people, particularly, those in the industry, when done correctly leads to more business opportunities for those that do not seek long-term industry engagement, but for those with high interest in long-term engagement can create a chance of getting internal promotion because people recommend the people they know and like. In addition, this opens paths for employment among young university graduates. Prying on the benefits leading scientists to engage in industry-based networking, especially for those that intend to startup their own businesses, networking helps to grow and gain a better position in the business operations. Networking in the industry is great for this regard because the value of networking is in the giving and receiving sort of beneficial exchange. To summarize the specific benefits of networking, the study explored and collected the points provided below;

i. Activeness - by just getting oneself to mingle and connect with peers in the industry is essential to move the scientist's career forward. This is regarded as the first step toward self-business enhancement;

ii. Candidness - candidness is a value resulting from networking. By consenting to be open, in return, the scientist is able to gain more information for their further research and also share information with others. This is basically a two-way idea exchange.

iii. Information - having discussed the benefit of openness in networking, it is guaranteed that when two or more people party together, information is shared and gained;

iv. Knowledge - The more information a scientist gain, the more significant is their research outcome in terms of converting science into industrial practices;

v. New leads - through networking, completely new ideas are created and discovered that can form new leads in research. Scientists can gain new ideas, methods, and approaches that they never thought of before.

vi. New contacts - networking leads to gaining new contacts for further recommendations in career jobs and business connections;

vii. Skills - Scientists develop skills and experience to handle certain situations such as how to solve a particular problem

viii. Reputation - networking cultivates one's reputation to grow as a scientist

ix. Support - it is natural that good reputation leads to gaining support from the contacts and even getting such support beyond the network circle because close contacts will help spread the positive word of mouth

x. Self-esteem - happiness and confidence are recipes gained from socializing and essential in building self-esteem which is beneficial for business growth and advancing position as a scientist. 


\author{
Mostak Ahamed Galib, Kamrun Nahar Munny, Akmal Khudaykulov \\ Enhancing university -industry collaboration: What are the drivers of academic researchers' involvement in \\ industry? \\ Proposition 3: Networking has a positive relationship with industry engagement.
}

\title{
ACCESS TO RESOURCES
}

Materials and data are necessary for any research in order to bring out quality research. Such materials and data may be obtained in the industry which compels researchers toward industry involvement. There exist a gap between data obtained by an outside researcher and an industry involved researcher who observes and is practically involved in the activities. Comparatively, in obtaining factual data we posit that an involved researcher does obtain needed data and materials with ease. The concept of knowledge cannot go undiscussed when researching on motives of scientist to engage in the industry. Therefore, knowledge is valuable resource that researchers are interested to gain since industrialized economies have prompted a shift in importance of intellectual assets over the endowment of natural resources ((Hansen et al., 1999). Hence, the disclosure of valuable knowledge enables scientist to validate and expand knowledge from the prior works. Appetite for knowledge as a resource motivates scientists to engage in industry to gain some knowledge with different dimension relative to academia.

Among the motives of researchers engaging in industry is accessibility of the state of art equipment, facilities and instrument. For this reason, scientists pursue careers in industry to establish relationships so that organizations can provide equipment accessibility and other research related opportunities for scientists to exploit (Owen-Smith and Powell 2001). Some fields of study require direct contact with the subject and object under investigation, for instance, researchers in the field of chemistry and material sciences need cutting edge laboratories, facilities and equipment in advancing their theories and practices. Such facilities and equipment can be costly to acquire as an individual and may not be found in academia. Therefore, the industry serves as the provider of such amenities. Additionally, researchers tend to involve themselves in the industry to discover new ideas and gain knowledge for research purposes through access to expertise and experience of industry employees. Industry employees can be valuable source of ideas and know-how; by working in collaborations, new ideas are formed and knowledge sharing is embraced.

Other studies have also shown that scientists join the industry with the motive of seeking for information (Ridings \& Gefen, 2004). According to McQuail (1987), the quest for information acquisition includes finding out about relevant events and conditions that fit research later on in their careers even after they opt to return to academia. Additionally, motive for industry engagement also includes the search for advice on practical matters, opinion and resolution. Furthermore, scientists will engage in industry for further learning as it is known that learning never ceases, gaining a sense of security and also gratifying curiosity and interest in general. Industry engagement gives access to other set of intangible resources such as skills. This advantage offered by industry engagement is, in fact, an exceptionally valuable resource.

Power is an enormous advantage presented by correctly developed resource accessibility. Reaching out to a wider range of clusters is more valuable than belonging to a strong cluster with limited individuals due to the strong relation between the individuals (Ilut, 1997). In comparison, a scientist linked in a huge industry is able to enjoy the connections with valuable contacts and accessibility of resource in wider network than the one linked in a limited academia arena. Though a limited setup builds a strong bond among contacts but is viewed as a family which makes it difficult to reach a bigger amount of facilities and people. Wider connection is a leverage for scientists to get resources and support in their career paths by reaching a big amount of trust and a great capacity of crossing through a big number of clustered links in both academia and within the industry (Grootaert, 1998; Putnam, 1993; Zak, 2001).

Proposition 4: Access to resources has a positive relationship with industry engagement.

\section{INDUSTRY PROBLEM SOLVING}




\section{Mostak Ahamed Galib, Kamrun Nahar Munny, Akmal Khudaykulov \\ Enhancing university -industry collaboration: What are the drivers of academic researchers' involvement in industry?}

Among the motives that drive researchers into industry involvement is to find answers and solutions to problems imminent in industries and also disclose problems caused by activities of the industry. Researchers have a wide variety of research interests; some focus on accelerating innovations in the production process and some focus on cooperate and social responsibility by advocating and pushing industries to embrace cleaner productions in their activities. Nevertheless, we sum up motives regarding problem solving toward industry engagement in the following bulleted points:

- $\quad$ Search for innovative and creative solutions to declining industries;

- Raising awareness and attentiveness of problems that industry confronts;

- Improving the foundation of understanding, in particular, phenomena i.e. new trends in the industry;

- They can also offer training in particular field for new recruits.

The motives listed above are well supported with the study done by Lee (2000) who argues that researcher builds a process of gaining knowledge on which efforts can be focused to raise awareness and provide alternative solutions and strategies applied for a particular problem which can be revisited in the future. Ulusoy et al. (2012) posit that an atmosphere conducive to problem solving and timing should be created and supplemented with materials needed to support the problem solving procedure.

A study done by Brandtzaeg and Heim (2009) found that one of the main confrontations for scientists engaging into the industry research is a swift change that is taking place in both technological developments and user inclinations, they desire to be involved in bringing such technological changes in the industry. Thus, some of the major motives or preferences to industry involvement may be stable over time because they connect to some basic needs in the industry (Brandtzaeg \& Heim, 2009). Technological advancement is a result of research and development, thus, research conducted on the basis of effective collaboration with the industry to advance technology and know-how on product and operations. Research collaborations are basically for innovation purposes by centering on joint research and development (R\&D) activities (Hagedoorn et al., 2000).

The theory of inventive problem solving encourages the search for innovative solutions to support the growing need for cooperate and social responsibility through promoting cleaner industrial operations. Researchers are not just ambitious in finding solutions in accelerating production capacity but also in solving industrial production problems, discovering weaknesses and developing opportunities within the industry and serving as an innovative instrument to find ways to improve environmental efficiency. Özbay and Demirer (2007) argue that environmentally concerned researchers engage in industry to stimulate preventive strategies that lessen the impacts of production processes on the environment. They further state that evaluating the impact of production on environment provides new opportunities for business optimization and savings. Drawing on these arguments, Frank et al., (2004) states that the problem solving explorations by researchers are focused on providing value to the industry, whilst they increase the reputation for extended industrial engagement and gain some economic returns in the process.

\section{Proposition 5: Industry problem solving has a positive relationship with industry engagement.}

\section{APPLICATION OF RESEARCH}

For researchers to be involved in the industry gives them a chance to prove practicality of their theoretical and curiosity driven research in the industry. According to study by Hawkins et al. (2012), $74.5 \%$ of researchers regard applicability of research to be highly important factor driving researchers toward industrial engagement. While $11.1 \%$ of researchers engage to seek IP rights (Hawkins, et al., 2012). Researchers contribute to industry by applying their studied methods in the seminars, publications, informative scientific prints and research projects and getting a team together working toward a common goal considering ethics of research, transforming research findings into industry practice. 


\section{Mostak Ahamed Galib, Kamrun Nahar Munny, Akmal Khudaykulov \\ Enhancing university -industry collaboration: What are the drivers of academic researchers' involvement in industry?}

Scientific research has made practical contributions in varying levels to the performance of various industries. The extent of research contributions have ranged from training given to graduates to tackle contemporary industrial problems or deficiencies to the development of models and tools necessary for producing marketable products, services and processes for further improvements in production systems. The disciplinary sources of these contributions have spanned the fields of engineering, natural and computer sciences, mathematics, as well as the social, behavioral, management, and policy sciences. Siegel et al., (2003) reported that 65 percent of the scientists interviewed in the study from different fields, particularly from engineering, computer and natural sciences, mathematics, as well as the social, behavioral, management and policy sciences indicated that engagement with the industry influenced their experimental work in a positive manner.

Scientists are more motivated when their research practically contributes to some advancement of industries. Grossman et al., (2001) showed four industries in which scientists practically contributed toward the development of industrial tools, prototypes, production processes, as well as product and service delivery to the market. Some field of research requires practical experiments to detect real situations, especially those discussed below which oblige scientists to directly engage in the industry before drawing any research conclusions. The four industries in which scientists were motivated to be engaged in order to prove their applied research are:

Aerospace: numerous scientists have the desire to work in this industry for varied reasons; practical experiments for those who typically specialize in this field. Contributions of applied research included advancement of nonintrusive instrumentation, flow visualization techniques and computational fluid dynamics (Grossman, Reid, \& Morgan, 2001). Moreover, specific technologies have been influenced by applied research, particularly, in the areas of providing internet by the use of satellite, combustion cooling and computational tools for data integration.

Medical devices and equipment: Devices have been developed in a wide range of medical therapeutic and diagnostic through joint involvement of academic researchers and academic medical centers in R\&D, evaluation, and clinical trials and development of prototype testing.

Financial services: Among the developments in financial services are financial risk management software, models for pricing derivatives and securities, new financial instruments, index funds, derivatives, financial information and research tools, risk credit metrics and advances in cryptography for specific applications of financial services.

Integrated logistics services: Applications for decision support systems, routing, production scheduling, logistics, distribution management and optimization modeling for shippers are result of academic researches.

Some reasons behind industrial engagement in regard to application of research are listed below;

- Keeping abreast of research conducted in the industry;

- Feedback from industry on viability of research;

- Exploitation of research capabilities and results or deployment know-how to obtain patents;

- Test application of ideas or theory aimed to explain and commercialize the ideas to the industry;

- Pursuing proprietary knowledge (patents);

- Promote innovation through knowledge and technology transfer;

- Academics' quest for recognition and achieve eminence and prestige.

Proposition 5: Application of research motive has a positive relationship with industry engagement 


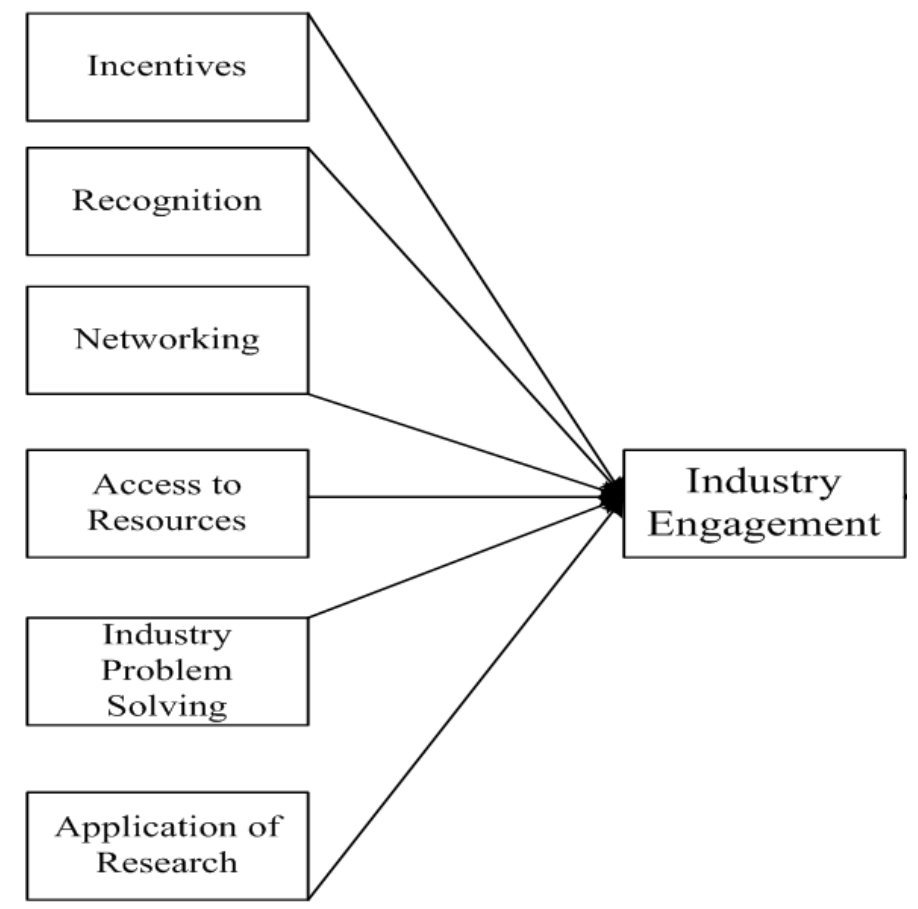

\section{DISCUSSION AND CONCLUSION}

The principal objective of this study is to find out what leads academics and researchers to engage in industry. By examining particular motives and their relationship to industry engagement, we aim to determine which factors companies should aim at managing in order to attain higher levels of researcher's engagement in the industry. By examining existing studies, we have built a general theory and constructed a model consisting of factors most conducive for scientists to engage in industry work. The findings of the study encompass identification of motives for the researchers' industry engagement. Through a detailed review of all factors belonging to the scope of motives that are opportunity-driven, key factors that are most conducive to researchers' industry engagement have been recognized. We have proposed the relationship between compensation and recognition, access to resources, belief about application of the research, networking opportunities and industry problem solving with industry engagement. According to our theory, these motives are significant drivers of industry engagement. Furthermore, industry engagement can be considered as a factor influencing organizational learning capability and organizational innovation performance. Our study provides new insight on aspects of university-industry relationships where existing studies are ambiguous and incomplete. Insofar, only qualitative analyses of factors contributing to researchers' industry engagement were conducted. Therefore, future study should explain why researchers engage in industry utilizing a qualitative method, thus, filling the existing research gap. Prior studies have used qualitative methods to investigate motives behind inclusion into industry, but have failed to determine the factors most conducive to the inclusion and participation. 


\section{REFERENCES}

- Adams, J. D., Chiang, E. P., Starkey, K., 2001. Industry-university cooperative research centers. The Journal of Technology Transfer 26 (1 - 2), 73-86.

- Agrawal, A., 2006. Engaging the inventor: Exploring licensing strategies for university inventions and the role of latent knowledge. Strategic Management Journal 27 (1), 63-79.

- Agrawal, A., Henderson, R. M., 2002. Putting patents in context: Exploring knowledge transfer from MIT. Management Science 48 (1), 44.

- Aiken, L. S., West, S. G., 1991. Multiple regression: testing and interpreting interactions. Thousand Oaks, Sage.

- Allen, T. J., 1988. Distinguishing engineers from scientists, in: Katz, R. (Ed.), Managing professionals in innovative organizations, Cambridge MA, Ballinger, pp. 3-18.

- Amabile, T. M., Patterson, C., Mueller, J., Wojcik, T., Odomirok, P. W., Marsh, M., and Kramer, S. J. 2001. Academic-practitioner collaboration in management research. A case of cross-professional collaboration. Academy of Management Journal, (44:2), pp. 418-431.

- Armbruster, H., Bikfalvi, A., Kinkel, S., \& Lay, G. (2008). Organizational innovation: The challenge of measuring non-technical innovation in large-scale surveys. Technovation, 28(10), 644-657.

- Asai, K., Ulusoy, G., \& Turksen, I. B. (2012). Computer integrated manufacturing: current status and challenges. Springer Publishing Company, Incorporated.

- Balachandra, R., \& Friar, J. H. (1997). Factors for success in R\&D projects and new product innovation: a contextual framework. Engineering Management, IEEE Transactions on, 44(3), 276-287.

- Balconi, M., Breschi, S., Lissoni, F., 2004. Networks of inventors and the role of academia: an exploration of Italian patent data. Research Policy 33 (1), 127- 145.

- $\quad$ Barber, B., \& Merton, R. K. (1957). Social stratification.

- Barker, D. 2004. The Scholarship of Engagement. A Taxonomy of Five Emerging Practices. Journal of Higher Education Outreach and Engagement, (9:2), pp. 123-137.

- Baskerville, R., Lyytinen, K., Sambamurthy, V., and Straub, D. W. 2011. "A response to the design-oriented information systems research memorandum," European Journal of Information Systems (20:1), pp. 11-15.

- Behrens, T. R., Gray, D. O., 2001. Unintended consequences of cooperative research: impact of industry sponsorship on climate for academic freedom and other graduate student outcome. Research Policy 30 (2), 179-199.

- Belkhodja, O., Landry, R., 2007. "The Triple-Helix collaboration: Why do researchers collaborate with industry and the government? What are the factors that influence the perceived barriers?" Scientometrics 70 (2), 301-332.

- Bercovitz, J., Feldman, M., 2003. Technology transfer and the academic department: who participates and why? Paper presented at the DRUID Summer Conference, Copenhagen.

- Blau, P. M., Falbe, C. M., McKinley, W., \& Tracy, P. K. (1976). Technology and organization in manufacturing. Administrative science quarterly, 20-40.

- Boyatzis, R. 1998. Transforming qualitative information: Thematic analysis and code development, Thousand Oaks, CA: Sage.

- Boyer, E. L. 1996. The scholarship of engagement. Journal of Public Service and Outreach, 1 (1), $11-20$.

- Brandtzæg, P. B., \& Heim, J. (2009). Why people use social networking sites. In Online communities and social computing (pp. 143-152). Springer Berlin Heidelberg.

- Bruneel, J., D'Este, P., and Salter, A. 2010. Investigating the factors that diminish the barriers to university-industry collaboration.

- $\quad$ Business \& Information Systems Engineering (2:5), pp. 283-293.

- Caloghirou, Y., Tsakanikas, A., Vonortas, N. S., 2001. University-industry cooperation in the context of the European framework programmes. TheJournal of Technology Transfer 26 (1 - 2), 153-161.

- Carroll, G., Hannan, M.T., 2000. The Demography of Corporations and Industries. Princeton University Press, Princeton, N.J.

- Caswill, C., and Shove, E. 2000. Introducing interactive social science. Science and Public Policy (27:3), pp. 154-157. 


\section{Mostak Ahamed Galib, Kamrun Nahar Munny, Akmal Khudaykulov \\ Enhancing university -industry collaboration: What are the drivers of academic researchers' involvement in industry?}

- Clark, B. R., 1998. Creating entrepreneurial universities: organizational pathways of transformation. New York; Oxford, Pergamon.

- Cockburn, I. M., Henderson, R. M., 1998. Absorptive capacity, coauthoring behavior, and the organization of research in drug discovery. Journal of Industrial Economics 46 (2), 157-182.

- Cockburn, I.M., Henderson, R.M., 1998. Absorptive capacity, coauthoring behavior, and the organization of research in drug discovery. Journal of Industrial Economics 46 (2), 157-182.

- Cohen, S. B., Florida, R., Coe, W. R., 1994. University-industry partnerships in the US. Pittsburgh, Carnegie-Mellon University.

- Cohen, W. M., Nelson, R. R., Walsh, J. P., 2002. Links and impacts: the influence of public research on industrial R\&D. Management Science 48 (1), 1-23.

- Cohen, W.M., Levinthal, D.A., 1990. Absorptive capacity: a new perspective on learning and innovation. Administrative Science Quarterly 35, 128-152.

- Cohen, W.M., Nelson, R.R., Walsh, J.P., 2000. Protecting their Intellectual Assets: Appropriability Conditions and Why U.S. Manufacturing Firms Patent (or Not). NBER Working Paper No. 7552.

- Cohen, W.M., Nelson, R.R., Walsh, J.P., 2002. Links and impacts: the influence of public research on industrial R\&D. Management Science 48 (1), 1-23.

- Cook, K. S., Hardin, R., \& Levi, M. (2005). Cooperation without trust?. Russell Sage Foundation.

- Dasgupta, P., David, P. A., 1994. Toward a new economics of science. Research Policy 23 (5), 487-521. 22

- Dasgupta, P., David, P.A., 1994. Toward a new economics of science. Research Policy 23 (5), 487-521.

- Davis, G. B., Massey, A. P., and Bjørn-Andersen, N. 2005. Securing the Future of Information Systems as an Academic Discipline.

- D'Este, P., Patel, P., 2005. University-industry linkages in the UK: what are the factors determining the variety of university researchers' interactions with industry? Paper presented at the DRUID conference, Copenhagen June 27-29.

- Deeprose, D. (1994). How to recognise and reward employees. New York: AMACOM.

- Ding, W.W., 2009. The Impact of Founder Professional Education Background on the Adoption of Open Science by for-Profit Biotechnology Firms. Working Paper.

- Etzkowitz, H., \& Leydesdorff, L. (2000). The dynamics of innovation: From National Systems and "Mode 2 " to a Triple Helix of university-industry-government relations. Research Policy, 29(2), 109-123.

- Feldman, M. P., \& Audretsch, D. B. (1999). Innovation in cities: : Science-based diversity, specialization and localized competition. European economic review, 43(2), 409-429.

- Ferragina, A., Pittiglio, R., \& Reganati, F. (2012). Multinational status and firm exit in the Italian manufacturing and service sectors. Structural Change and Economic Dynamics, 23(4), 363-372.

- Frank, R. J., George, J. P., \& Narasimhan, L. (2004). When your competitor delivers more for less. McKinsey Quarterly, (1), 48-59.

- Fukuyama, H., Guerra, R., \& Weber, W. L. (1999). Efficiency and ownership: evidence from Japanese credit cooperatives. journal of Economics and Business, 51(6), 473-487.

- Grossman, J. H., Reid, P. P., \& Morgan, R. P. (2001). Contributions of academic research to industrial performance in five industry sectors. The Journal of Technology Transfer, 26(1-2), 143152.

- Hagedoorn, J., \& Cloodt, M. (2003). Measuring innovative performance: is there an advantage in using multiple indicators?. Research policy, 32(8), 1365-1379.

- Hansen, M. T., Nohria, N., \& Tierney, T. (1999). What's your strategy for managing knowledge?. The Knowledge Management Yearbook 2000-2001.

- Harrin, E. (2006). Project Management in the Real World. British Informatics Society Limited.

- Helliwell, J. F., \& Putnam, R. D. (1995). Economic growth and social capital in Italy. Eastern Economic Journal, 295-307.

- Hernandez, P. A., Graham, C. H., Master, L. L., \& Albert, D. L. (2006). The effect of sample size and species characteristics on performance of different species distribution modeling methods. Ecography, 29(5), 773-785.

- Kahn, W. A. (1990). Psychological conditions of personal engagement and disengagement at work. Academy of management journal, 33(4), 692-724.

- King, R. G., \& Levine, R. (1993). Finance, entrepreneurship and growth. Journal of Monetary economics, 32(3), 513-542. 


\section{Mostak Ahamed Galib, Kamrun Nahar Munny, Akmal Khudaykulov \\ Enhancing university -industry collaboration: What are the drivers of academic researchers' involvement in industry?}

- Koeske, G. F., Kirk, S. A., Koeske, R. D., \& Rauktis, M. B. (1994). Measuring the Monday blues: Validation of a job satisfaction scale for the human services. Social work research, 18(1), 27-35.

- Lee, Y. S. (2000). The sustainability of university-industry research collaboration: an empirical assessment. The Journal of Technology Transfer, 25(2), 111-133.

- Macey, P. M., Woo, M. A., Kumar, R., Cross, R. L., \& Harper, R. M. (2010). Relationship between obstructive sleep apnea severity and sleep, depression and anxiety symptoms in newlydiagnosed patients. PLoS One, 5(4), e10211.

- Maskell, P., \& Lorenzen, M. (2004). The cluster as market organisation. Urban Studies, 41(5-6), 991-1009.

- McQuail, D. (1987). Mass communication theory: An introduction . Sage Publications, Inc.

- Nahapiet, J., \& Ghoshal, S. (1998). Social capital, intellectual capital, and the organizational advantage. Academy of management review, 23(2), 242-266.

- Owen-Smith, J., \& Powell, W. W. (2003). The expanding role of university patenting in the life sciences: assessing the importance of experience and connectivity. Research Policy, 32(9), 16951711.

- Özbay, A., \& Demirer, G. N. (2007). Cleaner production opportunity assessment for a milk processing facility. Journal of environmental management, 84(4), 484-493.

- Parsons, T. (1951). Illness and the role of the physician: A sociological perspective*. American Journal of orthopsychiatry, 21(3), 452-460.

- Perrin, A., Vidal, P., \& McGill, J. (2006). Valuing knowledge sharing in Lafarge. Knowledge and Process Management, 13(1), 26-34.

- Raider, H. J., \& Burt, R. S. (1996). Boundaryless careers and social capital. The boundaryless career: A new employment principle for a new organizational era, 42(2), 187-200.

- Ridings, C. M., \& Gefen, D. (2004). Virtual community attraction: Why people hang out online. Journal of Computer-Mediated Communication, 10(1), 00-00.

- Rotariu, T., \& Ilut, P. (1997). The sociological research and the opinion poll.

- Serageldin, I., \& Grootaert, C. (1998). 10. Defining social capital: an integrating view. Evaluation and Development: the institutional dimension, 1, 203.

- Stephan, P. E., \& Levin, S. G. (1992). Striking the mother lode in science: The importance of age, place, and time. Oxford University Press, USA.

- Uzzi, B., \& Dunlap, S. (2005). How to build your network. harvard business review, 83(12), 53.

- Vom Brocke, J., Simons, A., Niehaves, B., Riemer, K., Plattfaut, R., \& Cleven, A. (2009, June). Reconstructing the giant: On the importance of rigour in documenting the literature search process. In ECIS (Vol. 2009, pp. 2206-2217).

- Zak, P. J., \& Knack, S. (2001). Trust and growth. The economic journal, 111(470), 295-321. 